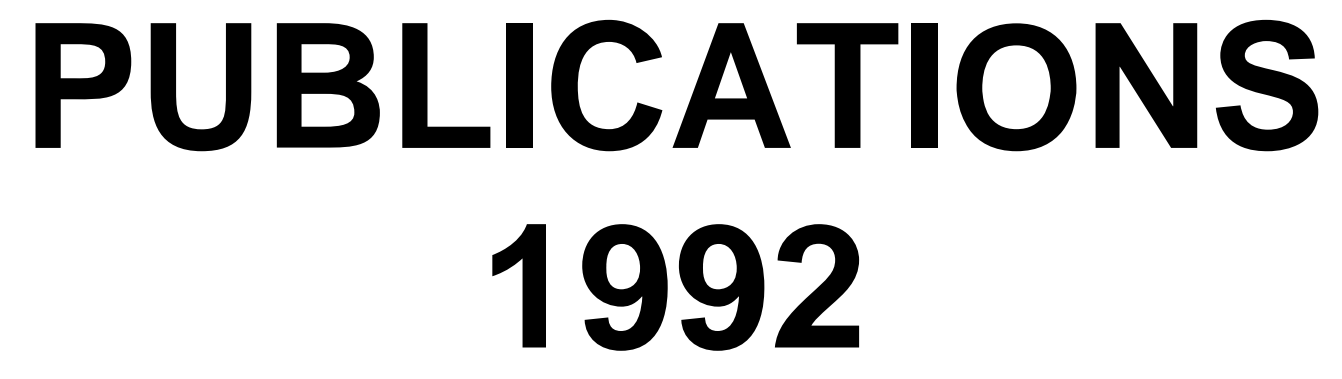




\section{FIELD DAY REPORT - 1992}

\section{Texas A\&M University Agricultural Research and Extension Center at Overton}

\section{Texas Agricultural Experiment Station \\ Texas Agricultural Extension Service}

Overton, Texas

April 30, 1992

\section{Research Center Technical Report 92-1}

All Programs and information of the Texas Agricultural Experiment Station and Texas Agricultural Extension Service are available to everyone without regard to race, color, religion, sex, age, or national origin.

Mention of trademark or a proprietary product does not constitute a guarantee or a warranty of the product by the Texas Agricultural Experiment Station or Texas Agricultural Extension Service and does not imply its approval to the exclusion of other products that also may be suitable. 


\title{
RABBITEYE BLUEBERRY PLANT RESPONSE TO NITROGEN AND PHOSPHORUS
}

\author{
V. A. Haby, J. V. Davis, and A. T. Leonard
}

Background. Acid, sandy soils selected for blueberry production are usually deficient in plant available phosphorus (P). Fertilizer addition at planting has not been a recommended practice. This glasshouse research was designed to study response of transplanted rabbiteye blueberry plants to fertilizer $\mathrm{P}$ and $\mathrm{N}$ rates.

Research Findings. Preplant phosphate was incorporated into $9.7 \mathrm{lb}$ of $1: 1 \mathrm{v} / \mathrm{v}$ loamy sand:peat mixture in a 2-gallon container at rates of 0,41, 82, 123 and $164 \mathrm{lb} \mathrm{P}_{2} \mathrm{O}_{5} / \mathrm{ac}$. Nitrogen was split-applied post-plant four times at 60-day intervals beginning 30 days after blueberry bushes were transplanted. Total $\mathrm{N}$ rates were equivalent to $0,100,200$, or $300 \mathrm{lb} / \mathrm{ac}$. Batches of $194 \mathrm{lb}$ of the sand-peat mixture were treated with $37.8 \mathrm{gm}$ of a fertilizer blend that contained $16 \% \mathrm{~K}_{2} \mathrm{O}, 9.4 \% \mathrm{Ca}, 8 \% \mathrm{Mg}, 8 \% \mathrm{~S}, 1 \% \mathrm{Zn}, 1 \% \mathrm{Fe}, 0.2 \% \mathrm{Cu}, 0.03 \% \mathrm{~B}$, and $0.01 \% \mathrm{Mo}$. Plants were harvested and separated into leaf, stem, and root components 270 days after transplanting.

Total plant growth increased as $\mathrm{N}$ rate increased (Table 1). Leaf and stem weight increases contributed to this linear response while root weight was not affected by fertilizer $\mathrm{N}$.

Table 1. Response of 'Tifblue' rabbiteye blueberry plants to fertilizer nitrogen and phosphorus.

\begin{tabular}{|c|c|c|c|c|c|}
\hline $\begin{array}{l}\text { Nitrogen } \\
\text { rate }\end{array}$ & $\begin{array}{l}\text { Leaf } \\
\text { D.M. }\end{array}$ & $\begin{array}{l}\text { Stem } \\
\text { D.M. }\end{array}$ & $\begin{array}{l}\text { Root } \\
\text { D.M. }\end{array}$ & $\begin{array}{l}\text { Total } \\
\text { Plant } \\
\text { D.M. }\end{array}$ & $\begin{array}{l}\text { Number } \\
\text { Stems } \\
>2 \mathrm{~mm}\end{array}$ \\
\hline lb/ac & \multicolumn{5}{|c|}{ - } \\
\hline 0 & 10.2 & 20.5 & 26.5 & 57.2 & 3.0 \\
\hline 100 & 14.0 & 23.4 & 30.1 & 67.2 & 3.8 \\
\hline 200 & 17.0 & 26.2 & 25.1 & 69.7 & 5.1 \\
\hline 300 & 21.4 & 30.7 & 30.3 & 82.4 & 4.8 \\
\hline Linear & $* * *^{2}$ & $* * *$ & N.S. & *** & $* * *$ \\
\hline Quadratic & N.S. & N.S. & N.S. & N.S. & N.S. \\
\hline \multicolumn{6}{|l|}{$\frac{\mathrm{P}_{2} \mathrm{O}_{5} \text { rate }}{\mathrm{lb} / \mathrm{ac}}$} \\
\hline 0 & 13.2 & 23.3 & 27.2 & 63.7 & 3.3 \\
\hline 41 & 11.2 & 20.3 & 23.9 & 55.4 & 3.2 \\
\hline 82 & 10.3 & 19.6 & 19.1 & 48.5 & 3.4 \\
\hline 123 & 23.0 & 32.3 & 38.5 & 95.7 & 6.3 \\
\hline 164 & 20.6 & 30.5 & 31.2 & 82.4 & 4.7 \\
\hline Linear & $* * *$ & $* * *$ & $* *$ & **** & $* * *$ \\
\hline Quadratic & $* * *$ & $* *$ & N.S. & $*$ & N.S. \\
\hline
\end{tabular}

${ }^{y}$ Dry Matter

$z_{* * *}, * *$, and $*$ indicate statistically significant linear or quadratic responses at $\mathrm{p}=0.01,0.05$, and 0.10 , respectively, due to treatment. 
Phosphorus at the 123 and $164 \mathrm{lb} / \mathrm{ac}$ rates increased total plant growth. Phosphorus applications increased leaf $P$ levels, but did not increase soil test $\mathbf{P}$ (data not shown).

The greatest yield response to the $\mathrm{N}$ and $P$ interaction occurred with plant top

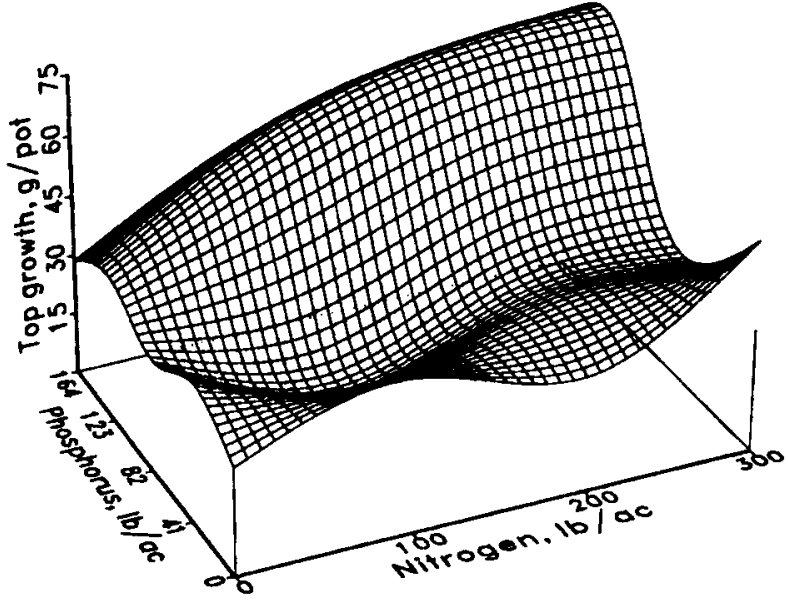

FIGURE 1. Robbiteye Blueberry Plant Response to the Interactions of Nitrogen and Phosphorus growth (Fig. 1). Except

for the high $N$ rate at the zero $P$ treatment, $N$ had no effect on plant growth at the 0,41 , and 82 lb $\mathrm{P}_{2} \mathrm{O}_{5}$ /acre application rates. There was a significant $(\mathrm{p}=0.01)$ linear response to $\mathrm{N}$ at $\mathrm{P}_{2} \mathrm{O}_{5}$ rates of 123 and $164 \mathrm{lb} / \mathrm{ac}$. The optimum $\mathrm{P}_{2} \mathrm{O}_{5}$ rate for fertilization of the soil:peat mixture in the planting hole under conditions of this experiment was the equivalent of $123 \mathrm{lb} / \mathrm{acre}$.

Application. Results from this research indicated that a rate of $\mathrm{P}_{2} \mathrm{O}_{5}$ equivalent to 123 $\mathrm{lb} / \mathrm{ac}$ was needed to increase rabbiteye blueberry plant growth when the soil $\mathrm{pH}$ is between 5.0 and 5.5. This rate equates to $5.1 \mathrm{gm} 0-46-0$ per $50 \mathrm{lb}$ soil:peat mix (45 lb soil:5 lb peat). This amounts to approximately $0.2 \mathrm{oz}$ (1 slightly rounded teaspoon) 0-46-0 added to $45 \mathrm{lb}$ soil:5 $\mathrm{lb}$ peat, equivalent to three-fourths bushel to be placed into the planting hole. At pH below 5.0, increased levels of extractable $\mathrm{Al}$ occur in this potting medium and a higher rate of $\mathrm{P}$ may be needed for best plant growth. 